\title{
Smart article: a scientific crosstalk
}

\section{Vahid Haghpanah* and Marjan Saeedi}

Endocrinology and Metabolism Research Center, Endocrinology and Metabolism Clinical Sciences Institute, Endocrinology and Metabolism Research Institute, Tehran University of Medical Sciences, Tehran, Iran

*Correspondence: v.haghpanah@gmail.com

Edited by:

Mikko P. Tulppo, Verve, Finland

Modern science is fast-moving, and no laboratory can exist for long with a program based on old facilities. Innovation and renewal are required to keep a laboratory on the frontiers of science (Burton Richter).

An era of the huge expansion of the academic population which is accompanied by the extremely high scientific productivity inevitably causes confusion for scientists who can hardly read all the publications about their topic of interest (Godlee et al., 2000). In the 1980s, a decade which witnessed the explosion of technology, everybody was amazed at the evolution in the research, but nobody could envisage that this evolution would bring its own difficulties. This overwhelming flood of published material may be suggestive of the need for scientists to change their style of producing scholarly articles. The recent increasing trend of data production may even result in discouraging scholars from reading the works of one another thoroughly. This issue can even be exacerbated by the ever-increasing amount of knowledge production and its getting more accessible via the internet (Godlee et al., 2000; Abbott, 2008).

In coming years, scientific publications will be totally technology driven and print version of journals will become obsolete (Bailey and Pang, 2004; Liben-Nowell and Kleinberg, 2008). For the very genuine reason, the ecology of information should be changed in the future and our suggestion to solve this crisis of abundance of scholarly publishing is "Smart Article."
Smart article is actually an interactive searchable screen, a big transformation from print to beyond the screen. The content is not merely a digital version of a printed article; it is a totally new way of literary structure and interface transformation.

In fact smart articles are fully organized abstracts with smart backbone comprised of different virtual layers. Although each article is displayed in a single page, details are also available in an interactive question-answer based between manmachine. It means that smart searching of structures and substructures will be facilitated in an enhanced article which leads to mutual understanding between article and reader.

The structure of a smart article will be coherent and each segment or paragraph will be logically followed by another one. Unlike the conventional articles, more detailed information about each part including hypothesis, methods, results and the discussion will be available on the platform and the researcher will be able to find all the data he wants to know about, for example the materials and laboratory instruments with access to video, audio, and expandable images.

Therefore, by reading just one embedded searchable article, the researcher could obtain much more information compared with reading just one conventional article at the same time.

Smart article utilizes digital technology to provide a better research experience. The main objective of this technology is to preserve the message of an article and offer a new way of comprehending the concept in an attractive and unique style and provide researchers with the opportunity to find all the required information on his chosen topic with a simple real-time dialog.

\section{ACKNOWLEDGMENTS}

The authors would like to acknowledge Dr. M. R. Haidary for his comments on the manuscript.

\section{REFERENCES}

Abbott, A. (2008).The traditional future: a computational theory of library research. Coll. Res. Libr. 69, 524-545.

Bailey, C., and Pang, T. (2004). Health information for all by 2015? Lancet 364, 223-224. doi 10.1016/S0140-6736(04)16686-5

Godlee, F., Horton, R., and Smith, R. (2000). Global information flow. BMC News Views 1:4.

Liben-Nowell, D., and Kleinberg, J. (2008). Tracing information flow on a global scale using Internet chain-letter data. Proc. Natl. Acad. Sci. U.S.A. 105, 4633-4638. doi: 10.1073/pnas. 0708471105

Received: 29 May 2013; accepted: 12 June 2013; published online: 28 June 2013.

Citation: Haghpanah V and Saeedi M (2013) Smart article: a scientific crosstalk. Front. Physiol. 4:161. doi: 10.3389/fphys.2013.00161

This article was submitted to Frontiers in Clinical and Translational Physiology, a specialty of Frontiers in Physiology.

Copyright (C) 2013 Haghpanah and Saeedi. This is an open-access article distributed under the terms of the Creative Commons Attribution License, which permits use, distribution and reproduction in other forums, provided the original authors and source are credited and subject to any copyright notices concerning any third-party graphics etc. 